\title{
Children's Oncology Group
}

National Cancer Institute

\section{Source}

National Cancer Institute. Children's Oncology Group. NCI Thesaurus. Code C39353.

An $\mathrm{NCl}$-supported clinical cooperative group formed by the merger of the four national pediatric cancer research organizations: the Children's Cancer Group, the Interg roup Rhabdomyosarcoma Study Group, the National Wilms Tumor Study Group, and the Pediatric Oncology Group. The primary objective of the organization is to conduct clinical trials of new therapies for childhood and adolescent cancer. COG develops and coordinates clinical trials conducted at the 238 member institutions that include cancer centers of all major universities and teaching hospitals throug hout the U.S. and Canada, as well as sites in Europe and Australia. COG members include over 5000 cancer researchers. 